This is a postprint version of the following published document:

Martinez-Cisneros, C.S., Levenfeld, B., Varez, A.,

Sánchez, J.Y. (2016). Development of sodium-

conducting polymer electrolyes: comparison between

film-casting and films obtained via green processes.

Electrochimica Acta, 192, pp. 456-466.

DOI: $10.1016 /$ j.electacta.2016.02.011

(C) Elsevier 2016

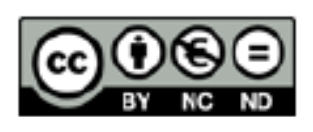

This work is licensed under a Creative Commons Attribution-NonCommercialNoDerivatives 4.0 International License. 


\title{
Development of sodium-conducting polymer electrolytes: comparison betweenfilm-casting and films obtained via green processes
}

\author{
C.S. Martinez-Cisneros ${ }^{\mathrm{a}}$, B. Levenfeld ${ }^{\mathrm{a}}$, A. Varez ${ }^{\mathrm{a}}$, J.Y. Sanchez ${ }^{\mathrm{a}, \mathrm{b}, *}$ \\ ${ }^{a}$ Materials Science and Engineering Department, University Carlos III of Madrid, Spain \\ ${ }^{\mathrm{b}}$ UJF UdS, Grenoble INP, LEPMI, UMRCNRS5279, 1130 Rue Piscine, BP75, F-38402 St Martin d'Hères, France
}

\begin{abstract}
Keywords:
sodium battery solvent-free

electrolyte energy storage

polyethylene oxide PEO

green chemistry
\end{abstract}

\begin{abstract}
A B S T R A C T
Sodium-conducting solvent-free polymer electrolytes based on commercially available and inexpensive materials poly(oxyethylene), $\mathrm{POE}$, and three different sodium salts $\left(\mathrm{NaI}, \mathrm{NaCF}_{3} \mathrm{SO}_{3}\right.$ and $\mathrm{NaClO}_{4}$ ) were prepared and exhaustively characterized. In order to minimize the environmental impact related to conventional film processing based on casting, a combination of lyophilization and hot-pressing was successfully applied. Contrary to film-casting, this new approach led to very homogeneous and pore-free films. This study suggests the obtained polymer electrolyte films as a promising route to enhance not only ionic conductivity but also mechanical properties. Furthermore, a preliminary work on salt blends hosted by POE shows that they strongly decrease melting point and crystallinity of the polymer electrolytes and paves the way for enhanced sodium-conducting materials.
\end{abstract}

\section{Introduction}

Nowadays, electrochemical energy storage extensively relies on Lithium-Ion Batteries (LIB). Stimulated by the demand of portable electronics, the trend has been tremendously accelerated by delocalized energy management needs (smart grids) and electric vehicles $[1,2]$ and it is expected to explode in the future. Such expected increase of LIB production has put back on stage the current and unsolved debate about lithium resources. They are actually very limited, since lithium is only the $33^{\text {rd }}$ most abundant element on Earth and its heterogeneous distribution is mainly concentrated in South America [3]. Therefore, the lithium cost has significantly increased during the last 30 years and will continue with the expected growth of LIB markets. Hence, not only regarding economic reasons, but also preservation of Earth resources, it is necessary to anticipate its substitution by more abundant elements and to start focusing on post LIB. Given their high availability and low cost, alkaline elements such as $\mathrm{Na}$ and $\mathrm{K}$, and alkaline-earth ones such as $\mathrm{Mg}$ and $\mathrm{Ca}$, emerge as promising candidates. With a redox potential of $-2.71 \mathrm{~V} v s$ SHE and theoretical capacities of $1.2 \mathrm{Ah} / \mathrm{g}$ and $1.1 \mathrm{Ah} /$ $\mathrm{cm}^{3}, \mathrm{Na}$ presents physical and chemical properties close to $\mathrm{Li}$

\footnotetext{
* Corresponding author at: Materials Science and Engineering Department, University Carlos III of Madrid, Spain. Tel.: +34916249447.

E-mail address: jeasanch@ing.uc3m.es (J.Y. Sanchez).
}

(3.8 Ah/g and $2.1 \mathrm{Ah} / \mathrm{cm}^{3}$ ) [4], and therefore, a similar behavior. Thus, the search for new electrodes and electrolytes for sodium batteries (SB) should benefit from previous learning of $\mathrm{Li}$ ones. Despite the $1^{\text {st }}$ proof of concept was demonstrated more than 30 years ago [5,6], SB technology has recently attracted a growing interest [7-9]. Indeed, developments were performed on both $\mathrm{Na} / \mathrm{S}$ $[10,11]$ and $\mathrm{Na} / \mathrm{NiCl}_{2}$ (ZEBRA) [12,13] batteries 25 years ago. These batteries, operating at high temperature, are mainly dedicated to stationary applications and use $\beta$-Alumina as electrolyte. In order to move successfully from LIB to SB, low and medium temperature operating batteries should be attainable to cover the LIB markets, including portable electronics, electric vehicles and smart grids. Therefore, the achievement of high performance SB calls for reliable electrolytes for both $\mathrm{Na}$-ion and Na-polymer batteries. The formers require liquid electrolytes in combination with porous or dense separators (gelled or plasticized polymer electrolytes). Following this approach, Stallworth et al. investigated PAN gelled electrolytes by ${ }^{23} \mathrm{Na}$ NMR and Impedance spectroscopies [14], Egashira et al. characterized $\mathrm{Na}$ tertiary liquid electrolytes incorporating a tetrafluoroborate ionic liquid, PEGDME and $\mathrm{NaBF}_{4}$ [15]. Furthermore, Bhide et al. [16] reported EC-DMC Na electrolytes, claiming that $\mathrm{NaPF}_{6} / \mathrm{EC}$-DMC leads to a stable surface film on $\mathrm{Na}_{0.7} \mathrm{CoO}_{2}$, enabling reversible cycling. Kumar et al. used Na-triflate in EMI-Tf to swell PVDf-HFP [17] and Ding et al. evaluated the effect of temperature and $\mathrm{Na}^{+}$concentration on liquid electrolytes [18]. Cao et al. [19] reported the development of polymer electrolytes 
based on perfluorinated sulfonic membranes in their Na-form, which were swelled in ethylene carbonate - propylene carbonate (EC-PC; v:v, 1:1) to produce ion-exchange membranes also acting as separators in Na-ion batteries. To improve mechanical properties of ambient-temperature Na-ion batteries, composite polymer electrolytes made of PVdF-HFP copolymer reinforced by glass-fiber were also proposed [20]. Recently, the potentiality of UV-induced photopolymerization of an oligoether precursor was claimed as a feasible and scalable solvent-free process to prepare amorphous cross-linked polymers to be swelled by Na-ion liquid electrolytes [21]. Regarding polymer electrolytes, Na indeed preceded Li with the pioneering works of P.V. Wright et al. on NaI, NaSCN and poly (oxyethylene) POE complexes [22-25]. In more recent contributions, Na salts hosted in PVA (polyvinyl alcohol) or in PAN (polyacrylonitrile) have been reported [26,27]. Nevertheless, both PVA and PAN are questionable for SB, the former because of its hydroxyl groups $(\mathrm{OH})$, and the latter because of the acidity of its tertiary proton $[28,29]$. Additionally, the high conductivity reported for such polymer electrolytes could be probably due to traces of water or remaining solvents. A publication from J. Serra-Moreno et al. [30] on POE/NaTFSI/SiO 2 nanocomposite electrolytes shows interesting conductivity. However, at the typical salt concentration range of polymer batteries, i.e. $30 \leq 0 / \mathrm{M} \leq 20$, these POE/NaTFSI composite electrolytes are semi-crystalline, melting between $64^{\circ} \mathrm{C}$ and $61{ }^{\circ} \mathrm{C}$ with crystallinity degrees of $55 \%$ and $42 \%$, respectively, whereas amorphous cross-linked NaTFSI electrolytes exhibited, at $\mathrm{O} / \mathrm{Na}=20$, conductivities reaching 0.02 and $0.8 \mathrm{mS} \cdot \mathrm{cm}^{-1}$ at $25^{\circ} \mathrm{C}$ and $80^{\circ} \mathrm{C}$, respectively, without any hysteresis [31]. Boschin et al. [32] presented a fundamental study regarding the influence of morphology and ion association (NaFSI and NaTFSI) on the performance of POE-based polymer electrolytes. In order to favor the electrode/electrolyte interface, Na-CMC, the sodium form of carboxymethyl cellulose used as additive in the electrode formulation, was found to reinforce the POE electrolyte when blended with $\mathrm{POE} / \mathrm{NaClO}_{4}$ [33]. Ni'mah et al. [34] introduced $\mathrm{TiO}_{2}$ nanoparticles to decrease crystallinity in $\mathrm{POE}-\mathrm{NaClO}_{4}$ polymer electrolytes, reporting only a discrete increase in conductivity from $1.35 \times 10^{-4} \mathrm{~S} \mathrm{~cm}^{-1}$ to $2.62 \times 10^{-4} \mathrm{~S} \mathrm{~cm}^{-1}$ at $60^{\circ} \mathrm{C}$ for the composition $\mathrm{O} / \mathrm{Na}=20$. Several approaches dealing with lithium-polymer electrolytes could be revisited for sodium ones as e.g. fully organic cross-linked host polymers [31,35-37] or hybrid organic-inorganic ones made, by solgel, from trialkoxysilanes [38].

Mainly due to the relative scarcity of data regarding $\mathrm{Na}$ conducting POE electrolytes, it was decided, in this study to focus on commercial POE as host polymer and on well-known commercial Na salts. Although POE $5 \cdot 10^{6} \mathrm{~g} /$ mole is often used as host, it was recently demonstrated that even a mild shearing of POE solutions produces a dramatic decrease of chain lengths [39]. Hence, in this work, POE $3 \cdot 10^{5} \mathrm{~g} /$ mole and three fairly inexpensive $\mathrm{Na}$ salts ( $\mathrm{NaI}, \mathrm{NaCF}_{3} \mathrm{SO}_{3}$ and $\mathrm{NaClO}_{4}$ ) were selected for Na polymer electrolytes preparation. Furthermore, special attention was also paid to the impact of the film elaboration process on the polymer electrolyte performance. In consequence, the assessment of reliable, economic and environmental friendly organic solventfree processes regarding conventional film-casting was performed. In this sense, films prepared from organic solutions were compared with those prepared by a combination of lyophilization and hot-pressing (LHP). Additionally, the effect of Na salt blends was also investigated.

\section{Experimental}

\subsection{Materials and polymer films preparation}

All reagents were supplied by Sigma-Aldrich in analytical grade. Sodium iodide (NaI), sodium trifluoromethane sulfonate
$\left(\mathrm{NaCF}_{3} \mathrm{SO}_{3}\right)$ and sodium perchlorate $\left(\mathrm{NaClO}_{4}\right)$ were used with POE host $\left(\mathrm{M}_{\mathrm{w}} 3 \times 10^{5} \mathrm{~g} / \mathrm{mol}\right)$. As a first approach, all solutions were prepared with an intermediate $\mathrm{O} / \mathrm{Na}$ ratio of 20 . In this sense, specific amounts of polymer and salts were dissolved by stirring during six hours in acetonitrile (ACN) and deionized water for filmcasting and LHP, respectively. For film-casting films, solutions were degassed to remove air bubbles and later poured into glass petri dishes covered by a PTFE film (Bytac ${ }^{\circledR}$ surface protection laminate, Sigma-Aldrich). The solvent was slowly evaporated at room temperature during 48 hours. Using this methodology, films with thickness in a range from $120 \mu \mathrm{m}$ to $165 \mu \mathrm{m}$ were obtained. For LHP films, solutions were frozen at $-20^{\circ} \mathrm{C}$ and later lyophilized (FreeZone ${ }^{1}$, LABCONCO, USA) during 48 hours. Afterwards, the material so obtained was hot pressed between two stainless steel plates $\left(100 \times 100 \times 5 \mathrm{~mm}^{3}\right)$ applying pressure and temperature $\left(50 \mathrm{kN} ; 100^{\circ} \mathrm{C}\right)$. The films so obtained had a thickness ranging from $75 \mu \mathrm{m}$ to $100 \mu \mathrm{m}$. Films obtained by both approaches were subsequently dried under vacuum at $50^{\circ} \mathrm{C}$ during 12 hours to eliminate residual traces of solvents and later stored in vacuum to avoid moisture absorption.

\subsection{Scanning electron microscopy}

The structural/morphological characterization of the films was performed using a Philips XL-30 scanning electron microscope (SEM) operating at $10 \mathrm{kV}$. For avoiding surface charge effects, before imaging, samples were gold coated using the sputter coater Polaron SC7610 (Fision Instruments, UK) at $18 \mathrm{~mA}$ under $1 \times 10^{-2} \mathrm{mbar}$ vacuum for 2 minutes.

\subsection{X-Ray diffraction}

X-Ray diffraction (XRD) measurements were carried out using a Philips X'PERT MPD diffractometer ( $\mathrm{Cu} K \alpha$ radiation) operating at $40 \mathrm{kV}$ and $40 \mathrm{~mA}$. The XRD patterns were recorded over a $2 \theta$ range of $5-80^{\circ}$ using a step scan of $0.02^{\circ}$ and a counting time of 1 sec per step.

\subsection{Thermal and thermomechanical analyses}

The thermogravimetric analysis (TGA) of the samples was performed using a Pyris ${ }^{1}$ TGA (Perkin Elmer, USA) thermogravimetric analyzer. Samples were heated in a platinum crucible from $30^{\circ} \mathrm{C}$ to $400^{\circ} \mathrm{C}$ at a heating rate of $10^{\circ} \mathrm{C} / \mathrm{min}$ under air atmosphere. Onset temperature $\left(\mathrm{T}_{\text {onset }}\right.$ ) was determined as the point of intersection of the tangent drawn at the point of greatest slope with the extrapolated base line. For differential scanning calorimetry (DSC) studies, we used a DSC822e (Mettler Toledo, Switzerland) under a $50 \mathrm{~mL} / \mathrm{min}$ constant $\mathrm{N}_{2}$ (g) flow. A first scan to eliminate any residual solvent was applied from $30^{\circ} \mathrm{C}$ to $150^{\circ} \mathrm{C}$ $\left(10^{\circ} \mathrm{C} / \mathrm{min}\right)$. At the same rate, samples were then cooled down and heated up from $-100^{\circ} \mathrm{C}$ to $250^{\circ} \mathrm{C}$ to determine melting temperature $\left(\mathrm{T}_{\mathrm{m}}\right)$, enthalpy of fusion $\left(\Delta \mathrm{H}_{\mathrm{m}}\right)$ and glass transition temperature $\left(\mathrm{T}_{\mathrm{g}}\right)$. The relative percentage of crystallinity $\left(\mathrm{X}_{\mathrm{c}}\right)$ was directly related to the area under the $1^{\text {st }}$ melting peak by using the equation [40]:

$X_{c}=\Delta H_{m} / \Delta H_{m}^{0} \times 100 \%$

where $\Delta \mathrm{H}_{\mathrm{m}}$ is the melting enthalpy estimated experimentally and $\Delta \mathrm{H}^{\circ}{ }_{\mathrm{m}}$ is the melting enthalpy for POE $100 \%$ crystalline $\left(213.7 \mathrm{~J} \cdot \mathrm{g}^{-1}\right.$ [41]). $\mathrm{T}_{\mathrm{g}}$ was estimated as the intersection of the tangent drawn through the heat capacity jump with the base line recorded before the transition. The uncertainty of the measurements was estimated to be $\pm 1^{\circ} \mathrm{C}$.

Dynamic Mechanical Thermal Analyses (DMTA) on samples $2.5 \times 4 \mathrm{~mm}^{2}$ were conducted using a DMA Q800 (TA Instruments, 
USA) working in tensile mode at $1 \mathrm{~Hz}$ and an oscillation amplitude of $15 \mu \mathrm{m}$. DMTA measurements were carried out by heating samples from $-100^{\circ} \mathrm{C}$ to $+90^{\circ} \mathrm{C}$ at a heating rate of $5^{\circ} \mathrm{C} / \mathrm{min}$.

\subsection{Ionic conductivity measurements}

The evaluation of the electrical behavior of the films was carried out by Impedance Spectroscopy (IS) using an Impedance/GainPhase Analyzer SI1260 (Solartron, UK). Impedance tests were performed by applying a $100 \mathrm{mV}$ amplitude signal in the $1 \mathrm{~Hz}-$ $10 \mathrm{MHz}$ frequency range. Measurements at different temperatures while heating $\left(20^{\circ} \mathrm{C}-95^{\circ} \mathrm{C}\right)$ were carried out using stainless steel blocking electrodes ( $\Phi=5 \mathrm{~mm}$ ) embedded in a Swagelok-Teflon cell introduced in a programmable climatic chamber (BINDER, Germany). To obtain reproducible measurements, we established a dwell time of 15 minutes before taking every measurement, this time was enough for the system to reach a stable temperature.

\section{Results and Discussion}

\subsection{Film processing}

Film-casting is the usual laboratory route to process polymer electrolyte films. Although easy, this processing is far from being obvious and a recent report [42] emphasizes the impact of solvents used to cast multiblock copolymers on the membrane's performance. The situation appears simpler in case of POE electrolytes, but the presence of a salt and the semi-crystalline nature of the host polymer might generate plenty of heterogeneity. Alternatives to film-casting include extrusion and hot-pressing. Extrusion involves a preliminary compounding of polymer, salt and possible additives, as a premix. Nevertheless, given the Melt Flow Index (MFI) and the sensitivity of POE to chain breaking [39], the molecular weight of POE should be limited to roughly 300,000 g/ mole. This process, well-adapted to industrial upscaling, was successfully used to process ionomers into Fuel Cell Membranes, using water-soluble plasticizers to decrease the MFI $[43,44]$. On the other hand, hot-pressing is a solvent-free process used for shaping composites and polymers from powders. Colò et al. proposed a green approach based on the film casting of aqueous POE electrolyte solutions followed by hot-pressing [33]. We selected a two-steps process involving lyophilization (freeze-drying) of POE-salt aqueous solutions followed by hot-pressing of the evenly distributed POE/salt powders. Electrochemical materials have been early processed by hot-pressing to produce electrodes based on electron-conducting polyethylene films [45]. More recently, POE nanocomposite electrolytes [46] were processed by hotpressing. Nevertheless, as such nanocomposites involve a
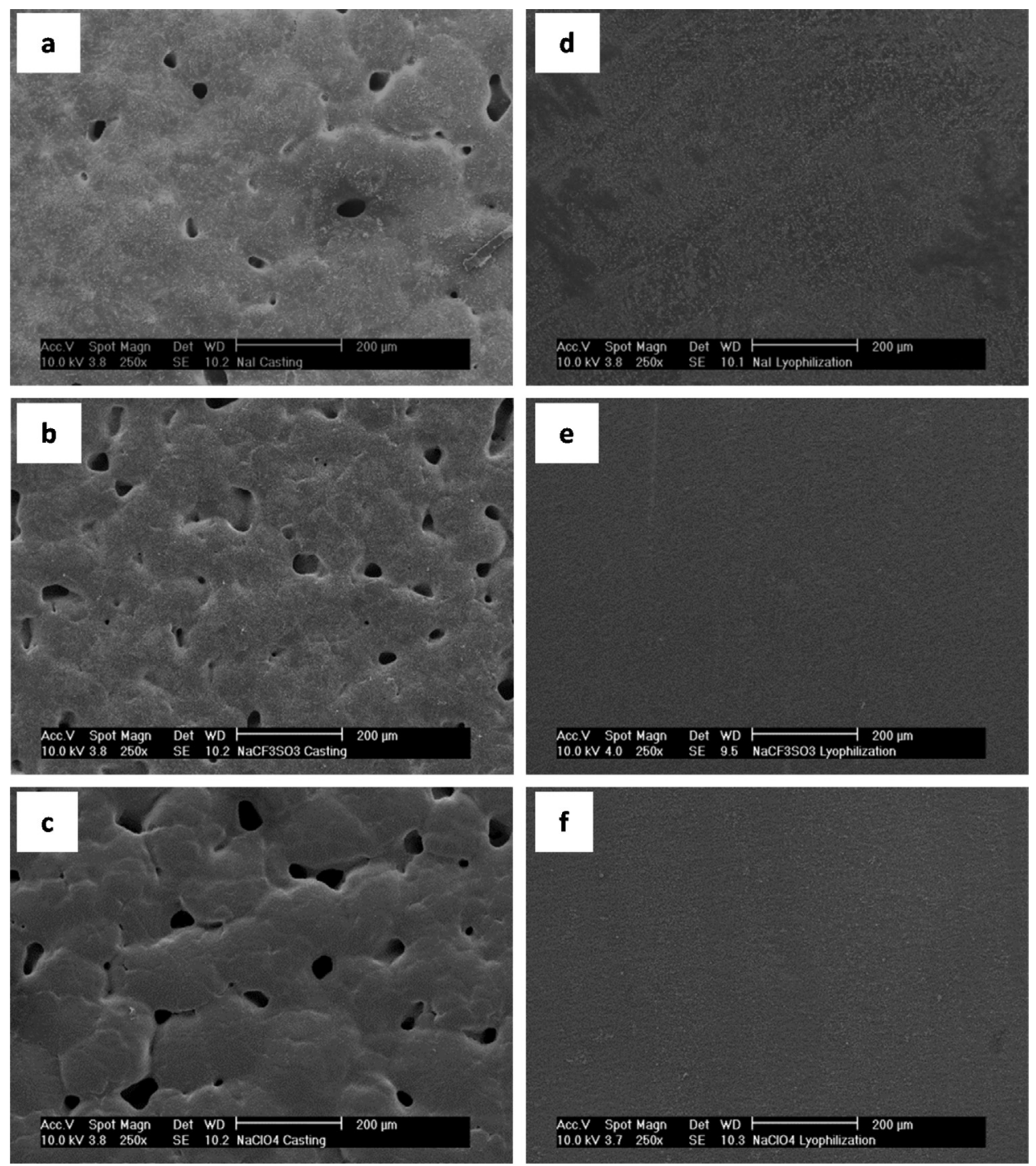

Fig. 1. SEM images of POE-Na polymer electrolytes prepared by film-casting (a, b, c) and LHP (d, e, f) based on NaI, $\mathrm{NaCF}_{3} \mathrm{SO}_{3}$ and $\mathrm{NaClO}_{4}$, respectively. 
preliminary ball-milling step, lyophilization becomes useless. On the other hand, it can be feared that ball-milling, a convenient technique to get homogeneous dispersion of fillers, leads to POE chain's shortening [39]. The combination of lyophilization and hotpressing was reported to produce microporous polymeric blends made of PVdF and POE, but it was used only as an intermediary step [47]. Balsara et al. also used a lyophilization step to process their block copolymers (PS-POE) [48], but using the highly toxic and often prohibited benzene as a solvent. In this study, we processed Na-conducting POE electrolyte films by conventional film-casting from ACN solutions and by an organic solvent-free route using LHP. Electrolyte films' performances were compared.

\subsection{Microstructural analysis}

\subsubsection{Scanning electron microscopy (SEM)}

Fig. 1 presents the surface morphology of samples obtained either from film-casting or from hot-pressing of previously lyophilized materials (LHP). A remarkable difference in the surface roughness and texture of the polymer films can be clearly noticed. Despite carefully degassing solutions, films prepared by filmcasting (Figs. 1a-1c) present a highly porous surface with pore diameters ranging from 11 to $65 \mu \mathrm{m}$. Conversely, a compact and flat morphology of the surface was observed on films prepared by LHP (see Fig. 1d-1f). In this case, films present a much more homogeneous and pores-free surface. While macroporosity is essential for separators to be used in LIB, the lack of porosity is an indisputable asset for solvent-free polymer electrolyte films, since the presence of pores is detrimental to their mechanical performance. Furthermore, using the LHP approach, a higher control over the experimental conditions for the attainment of the films is achieved.

\subsubsection{X-Ray diffraction (XRD)}

The structural properties of $\mathrm{POE}$ and POE-Na salt complexes, based on $\mathrm{NaI}, \mathrm{NaCF}_{3} \mathrm{SO}_{3}$ and $\mathrm{NaClO}_{4}$, were investigated by XRD. The corresponding patterns, recorded at the same experimental conditions, are shown in Fig. 2. The semi-crystalline nature of POE was confirmed by the presence of two relatively broad peaks at $2 \theta=19.09^{\circ}$ and $23.23^{\circ}$, which correspond to those reported in the literature [49]. The XRD patterns of both, casted and LHP polymer electrolytes, presented a behavior similar to the host polymer one. Nevertheless, the dissolution of the sodium salts in POE caused a decrease in the intensity of the POE peaks, which can be ascribed to a decrease in crystallinity related to the $\mathrm{Na}^{+}$ solvation by the polyether chains. The most significant diffraction peak, observed in POE-NaI films, decreased 65\% and 38\% for casted and LHP films, respectively. Such decrease was higher than that of those electrolytes based on $\mathrm{NaClO}_{4}, 35 \%$ and $25 \%$, and $\mathrm{NaCF}_{3} \mathrm{SO}_{3}$, $32 \%$ and $38 \%$. This suggests a more amorphous structure for POE$\mathrm{NaI}$ electrolytes. This amorphization should result in higher ionic mobility and, therefore, higher ionic conductivity. It is also expected that as salt concentration increases, crystallinity should decrease [50,51], leading to higher ionic mobility. Despite patterns corresponding to $\mathrm{NaCF}_{3} \mathrm{SO}_{3}$ and $\mathrm{NaClO}_{4}$ based electrolytes present new peaks in the $20^{\circ}-23^{\circ}$ region, none of them correspond to the
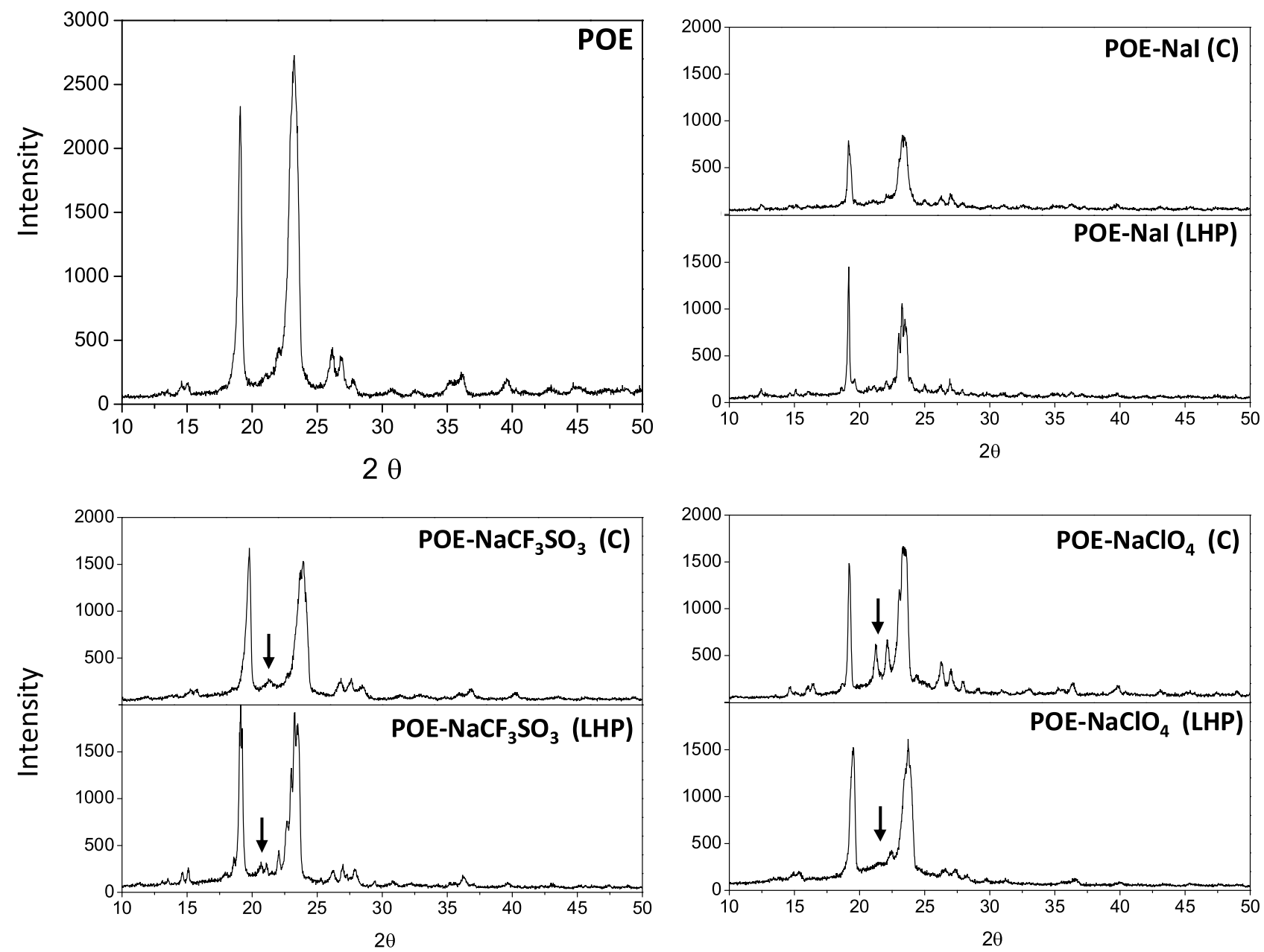

Fig. 2. XRD patterns of POE and polymer electrolytes (POE-NaX; O/Na=20); C: film-casting; LHP: lyophilization followed by hot-pressing. 
related salts. It may therefore be inferred that both salts perfectly dissolve in the host polymer.

\subsection{Thermal and thermomechanical behaviors}

\subsubsection{Thermogravimetric analysis (TGA)}

Fig. 3 shows the TGA curves obtained under air atmosphere for POE and POE-Na salt electrolytes prepared by film-casting and LHP. According to these results, there was no significant difference between casted and LHP electrolyte films. A very small weight loss at the low temperature region $\left(\mathrm{T}<100^{\circ} \mathrm{C}\right)$ was observed for all samples, which could be attributed to some humidification of samples during handling. Such weight loss was more evident in case of POE-NaI electrolytes, reaching a value of about $2 \mathrm{wt} \%$. This might be related to sublimation of iodine produced by partly oxidized iodide, since otherwise the hygroscopicity of the samples should be similar. Later on, a much more significant weight loss, ascribable to the polyether degradation, occurs. In case of POE, $\mathrm{T}_{\text {onset }}$ ranged from $213^{\circ} \mathrm{C}$ to $205^{\circ} \mathrm{C}$ for films prepared by casting and LHP, respectively. Regarding polymer electrolytes, $\mathrm{T}_{\text {onset }}$ shifted, in all cases, to $\mathrm{T}>240^{\circ} \mathrm{C}$. Instead of being related to improved thermal stability of POE when blended with a sodium salt, such delay could be attributed to a strong interaction between the salt molecules and chain fragments originated from thermal degradations. Cameron et al. [52] investigated, using a thermal volatilization analyzer (TVA), the thermal behavior, in vacuum, of NaSCN and $\mathrm{NaClO}_{4} / \mathrm{POE}$ complexes. In their conditions, the $\mathrm{T}_{\text {onset }}$ values were almost identical for POE and POE/NaSCN $\left(340-350^{\circ} \mathrm{C}\right)$, while the $\mathrm{T}_{\text {onset }}$ occurred at lower temperature for $\mathrm{NaClO}_{4} / \mathrm{POE}$. Afterwards, the rate of degradation was found to be higher for the thiocynate complex than for POE and almost explosive for the perchlorate one. Analyses of the residues showed sharp declines in $\mathrm{M}_{\mathrm{w}}$ for the whole of the samples. As Cameron samples were heated under vacuum and not in air, their $\mathrm{T}_{\text {onset }}$ values are higher than those observed in this work.

Thermal stability overtime is a relevant parameter for a reliable battery operation, since mechanical properties strongly depend on material degradation. Furthermore, in case of an exothermic event, the battery can be broken and the polymer electrolyte exposed to air at high temperature. Nevertheless, several works overestimate the thermal stability of polymer electrolytes, since TGA studies are mainly performed in a scanning temperature mode instead of an isothermal one and under an inert gas atmosphere (not in air). In this sense, to test stability over time, a thermal treatment was applied to the electrolyte composed by $\mathrm{POE}$ and $\mathrm{NaCF}_{3} \mathrm{SO}_{3}(\mathrm{O} /$ $\mathrm{Na}=20$ ) prepared by film-casting. The electrolyte was heated up from $30^{\circ} \mathrm{C}$ to $100^{\circ} \mathrm{C}$ at a constant rate of $10^{\circ} \mathrm{C} / \mathrm{min}$, and maintained there for 10 hours. As seen at the lower-right graph in Fig. 3, the electrolyte was found to be stable while kept at $100^{\circ} \mathrm{C}$ (dashed line), since only a negligible weight loss of about $0.14 \%$ was observed after the settled time. However, when temperature was set at $170^{\circ} \mathrm{C}$ (continuous line), a linear weight loss vs temperature was observed, leading to a total weight loss of roughly $13 \%$ after ten hours. Since operation temperature in most battery applications is usually below $100^{\circ} \mathrm{C}$, it could be assumed that these polymer electrolytes meet the thermal stability requirements to be used in Na batteries.

\subsubsection{Differential scanning calorimetry (DSC)}

DSC data $\left(\mathrm{T}_{\mathrm{m}}, \Delta \mathrm{H}_{\mathrm{m}}, \mathrm{X}_{\mathrm{c}}\right.$ and $\left.\mathrm{T}_{\mathrm{g}}\right)$ for POE and its electrolytes are gathered in Table 1. At the concentration used, i.e. $\mathrm{O} / \mathrm{Na}=20$, the salt has a fairly low impact on the melting temperature, $\mathrm{T}_{\mathrm{m}}$. On the other hand, crystallinity decreases more substantially, ranging from 31 to $58 \%$ and according to $\mathrm{NaI}<\mathrm{NaClO}_{4}<\mathrm{NaCF}_{3} \mathrm{SO}_{3}$. Regarding the effect of the preparation methodology, no significant differences, i.e. $\sim 1$ to $1.5 \%$, were observed for $\mathrm{NaClO}_{4}$ and $\mathrm{NaCF}_{3} \mathrm{SO}_{3} / \mathrm{POE}$ films. Nevertheless, in case of POE-NaI, $\mathrm{X}_{\mathrm{c}}$ increased from 31.4 to $39.6 \%$ when using LHP. Furthermore, due to polymer-

Table 1

Melting temperature, melting enthalpy, percent crystallinity and glass transition temperature for POE and POE-NaX electrolytes $(\mathrm{O} / \mathrm{Na}=20)$.

\begin{tabular}{|c|c|c|c|c|c|}
\hline Film & Methodology & $\mathrm{T}_{\mathrm{m}} /{ }^{\circ} \mathrm{C}$ & $\Delta \mathrm{H}_{\mathrm{m}} / \mathrm{J} \cdot \mathrm{g}^{-1}$ & $\mathrm{X}_{\mathrm{c}} / \%$ & $\mathrm{~T}_{\mathrm{g}} /{ }^{\circ} \mathrm{C}$ \\
\hline POE & powder as received & 66.7 & 155.6 & 73.1 & -55.5 \\
\hline POE-NaI & film-casting & 60.3 & 66.9 & 31.4 & -5.5 \\
\hline POE- $\mathrm{NaCF}_{3} \mathrm{SO}_{3}$ & film-casting & 62.2 & 125.1 & 58.5 & -15.2 \\
\hline $\mathrm{POE}-\mathrm{NaClO}_{4}$ & film-casting & 60.6 & 86.6 & 40.5 & -8.7 \\
\hline POE-NaI & hot-pressing & 61.7 & 84.7 & 39.6 & -5.4 \\
\hline $\mathrm{POE}-\mathrm{NaCF}_{3} \mathrm{SO}_{3}$ & hot-pressing & 61.6 & 121.8 & 56.9 & -15.7 \\
\hline POE-NaClO & hot-pressing & 60.7 & 88.6 & 41.5 & -8.5 \\
\hline
\end{tabular}
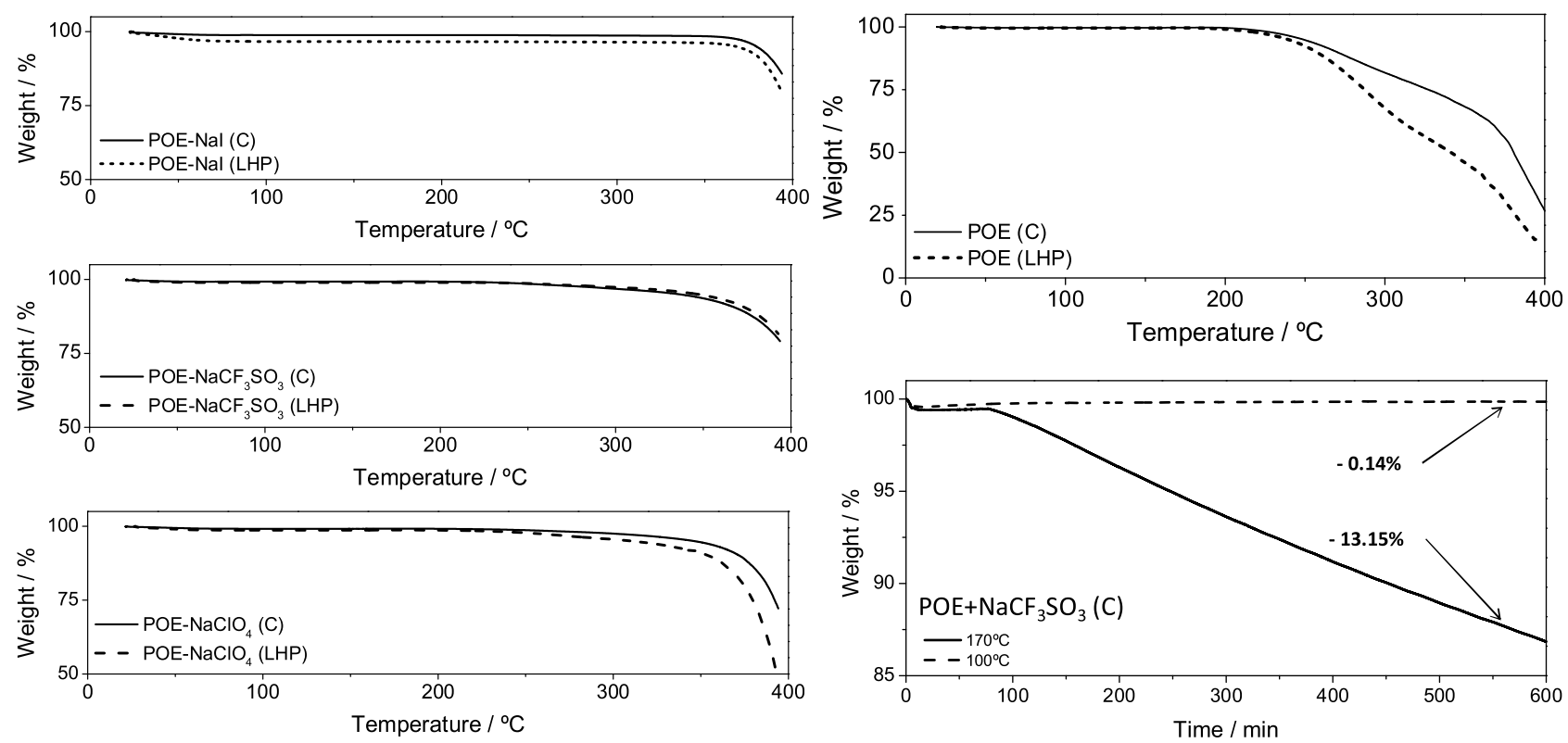

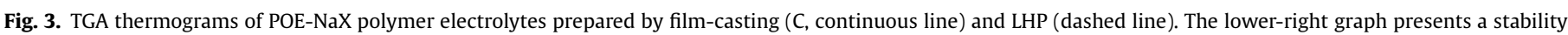
study performed on $\mathrm{POE}-\mathrm{NaCF}_{3} \mathrm{SO}_{3}$. 
salt interactions, in particular, physical or 'transient' cross-links (i.e. the salt solvation by several polyether chains), the dissolution of salts in POE increases $\mathrm{T}_{\mathrm{g}}$. On the other hand, ionic conductivity is governed by both, the content of free ions and solvent-separated ion pairs and their mobility. Ion's mobility in fully amorphous polymer electrolytes, in the operating temperature range of the related batteries, i.e. above $\mathrm{T}_{\mathrm{m}}$, depends on the segmental mobility of the polymer chains, which is reflected by $T_{g}$ values. Therefore, the $T_{g}$ of any semi-crystalline polymer does not represent the segmental mobility above $\mathrm{T}_{\mathrm{m}}$, since the amorphous phase is constrained by the crystalline one, resulting in an 'artificial' $T_{g}$ increase. Hence, the knowledge of $\mathrm{T}_{\mathrm{g}}$ corresponding to crystallinity-free POE electrolytes is essential. Performing a supercooling of POE-NaX to suppress the crystallinity, supposes a quenching of the melted electrolyte at very high speed, which is usually not possible with most commercial DSC equipment: electrolytes have enough time to crystallize during the cooling step. Therefore, the measured $\mathrm{T}_{\mathrm{g}}$ unfortunately does not more reflect the segmental mobility at $\mathrm{T}>\mathrm{T}_{\mathrm{m}}$.

\subsubsection{Thermomechanical behavior of POE-NaX electrolytes}

In solvent-free polymer electrolytes the host polymer behaves as a macromolecular solvent and should endow the polymer electrolyte with mechanical strength high enough to make unnecessary the use of a classical separator. High storage modulus allows the polymer electrolyte to be shaped into thin films, decreasing the electrolyte cost and increasing ionic conductance. It is therefore essential to know the storage modulus E' not only at ambient temperature, but also in the battery operating temperature range, i.e. at high temperatures. The temperature dependence of the mechanical properties of the electrolyte films as a function of sodium salt $(\mathrm{O} / \mathrm{Na}=20)$ and preparation methodology was investigated by DMTA. Fig. 4 shows the storage modulus (E') as a function of temperature from $-100^{\circ} \mathrm{C}$. The E' curves obtained for all polymer electrolytes correspond to the typical behavior expected for a one-dimensional semi-crystalline polymer material. Below $\mathrm{T}_{\mathrm{g}}$,i.e. the relaxation $\alpha$, E' values range between 4.5 and $6 \mathrm{GPa}$. Regarding $\tan \delta$, independently of the preparation methodology, one maximum was observed for the POE- $\mathrm{NaCF}_{3} \mathrm{SO}_{3}$ electrolyte. However, in case of POE-NaI and POE-NaClO maxima were obtained. This behavior might be ascribed as a microphase separation as reported by Moacanin et al. [53] for $\mathrm{LiClO}_{4}$ hosted in poly(oxypropylene), PPO. Prudhomme et al. [54] investigated PPO/LiX complexes and observed a microphase separation ( two $_{\mathrm{g}}$ were observed) for $\mathrm{O} / \mathrm{Li}$ below a given threshold, which was found to vary, according to the anion, from 9 to 16. In

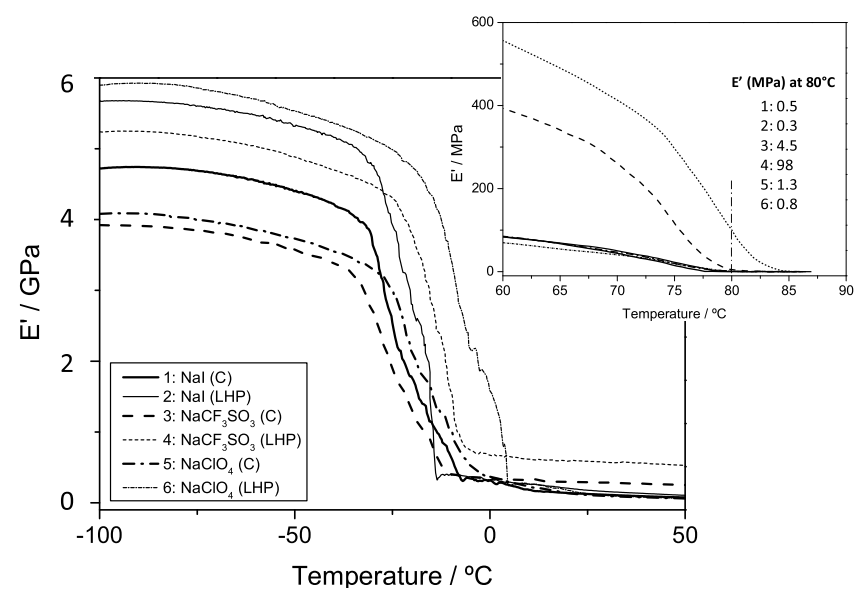

Fig. 4. Storage moduli (E') obtained by DMTA. Insert shows the region beyond the fusion, where most electrolytes still retain some mechanical properties. order to check whether microphase separation occurs or not, we annealed all samples at $90^{\circ} \mathrm{C}$ for 1 hour and repeated the DMTA assays from $-100^{\circ} \mathrm{C}$ to $90^{\circ} \mathrm{C}$. For both samples, i.e. NaI and $\mathrm{NaClO}_{4} /$ POE, a single $\tan \delta$ was observed, which allows concluding that microphase separation does not occur in our POE-NaX electrolytes. Regarding E', since mechanical strength is mainly caused by the crystalline phase, a neat decrease was observed in the temperature range $\mathrm{T}_{\alpha}<\mathrm{T}<\mathrm{T}_{\mathrm{m}}$. Due to the crystalline content decrease, E' values for $\mathrm{NaI}$ and $\mathrm{NaClO}_{4}$ electrolytes are significantly lower than those of $\mathrm{POE}$ and $\mathrm{POE}-\mathrm{NaCF}_{3} \mathrm{SO}_{3}$ electrolytes. Above $\mathrm{T}_{\mathrm{m}}, \mathrm{E}^{\prime}$ dropped dramatically, leading to the creeping of the polymer electrolytes from about $80^{\circ} \mathrm{C}$. This behavior is generally observed in unfilled polymer electrolytes based on commercial POE, unless a specific interaction involving the anion occurs, i.e. $\mathrm{POE} / \mathrm{C}_{6} \mathrm{~F}_{5}-\mathrm{SO}_{3} \mathrm{Li}$ electrolyte [55]. It is worth highlighting that E' exceeding $40 \mathrm{MPa}$ were obtained for the three polymer electrolytes above the melting temperature, independently of the elaboration process. Actually, E' values even up to $98 \mathrm{MPa}$ were reached at $80^{\circ} \mathrm{C}$ for $\mathrm{POE}-\mathrm{NaCF}_{3} \mathrm{SO}_{3}$ $(\mathrm{O} / \mathrm{Na}=20)$. Even though mechanical strength vanishes afterwards, making these polymer electrolytes unsuitable for Na-polymer batteries, these $\mathrm{E}^{\prime}$ values clearly demonstrate that $\mathrm{Na}^{+}$interchain solvation acts as a physical cross-link.

Regarding the impact of casting and LHP processing, films prepared by the latter exhibited higher E' than those prepared by film-casting at the low temperature range. Since the crystallinity contents are fairly close, these enhanced mechanical strengths should be, at least partly, attributed to the lack of porosity in films processed by LHP, as previously shown in SEM images.

\subsection{Ionic conductivity}

Besides being cheaper, the three salts selected for this study offer additional advantages regarding other options available in the market. NaI is intrinsically stable, as all Na halides, in reduction. Therefore, despite its limited stability in oxidation $\left(\mathrm{E}_{0}\right.$ vs $\mathrm{SHE}=$ $+0.54 \mathrm{~V}$ ), it could be advantageously used in batteries where high positive potentials are not used, such as $\mathrm{Na} / \mathrm{S}\left(\mathrm{E}_{0}\right.$ vs $\left.\mathrm{SHE}=-0.48 \mathrm{~V}\right)$. As all perchlorates, $\mathrm{NaClO}_{4}$ has remarkable electrochemical performances and can be considered as a reference salt even if its use, in commercial rechargeable batteries is, for safety reasons, questionable. Regarding $\mathrm{NaCF}_{3} \mathrm{SO}_{3}$, this salt is known for its thermal, chemical and electrochemical stability, making it an attractive candidate for batteries development. During this study, a first comparative screening was performed for all POE electrolytes at the same salt-concentration, $\mathrm{O} / \mathrm{Na}=20$. Hereinafter, sodium triflate was selected to study the conductivity dependence on salt concentration. Finally, to determine the effect of the simultaneous presence of two different salts in the same polymeric matrix, we attempted the use of 1:1 (in moles) blends of NaI with Na triflate and Na perchlorate.

\subsubsection{Room temperature conductivity}

Batteries based on semi-crystalline polymer electrolytes can only operate above their melting temperature, $\mathrm{T}_{\mathrm{m}}$, i.e. in their amorphous state. Nevertheless, valuable information can be also inferred from the knowledge of the conductivity below $T_{m}$ regarding the impact of the process. Fig. 5 shows complex impedance plots obtained at room temperature $\left(20^{\circ} \mathrm{C}\right)$ for all electrolytes. Nyquist plots comparison shows that independently of the used salt, the film-casting process leads to slightly higher conductivity when compared to LHP, being the lowest gap obtained for $\mathrm{POE}-\mathrm{NaCF}_{3} \mathrm{SO}_{3}$. In general, when comparing DSC measurements with conductivity data, they fit with the conventional approach, ascribing the lowest conductivity to the highest crystallinity degree, since LHP-processed films mostly exhibited slightly higher $\mathrm{T}_{\mathrm{m}}$ and crystallinity degree than the casted ones. 

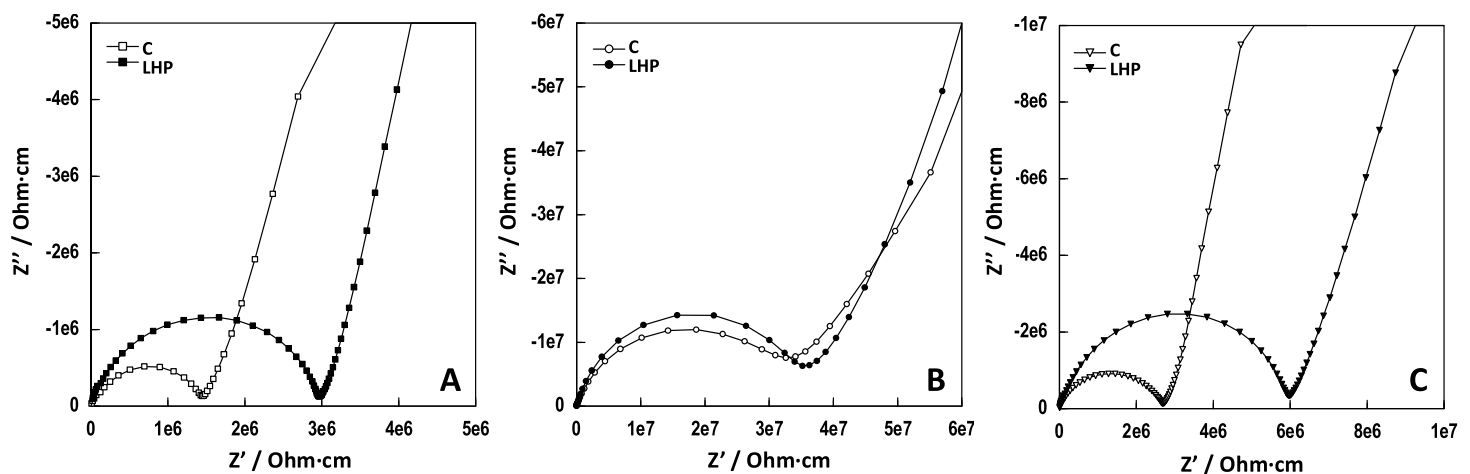

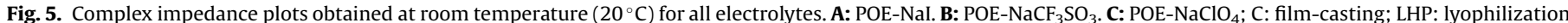
followed by hot-pressing.
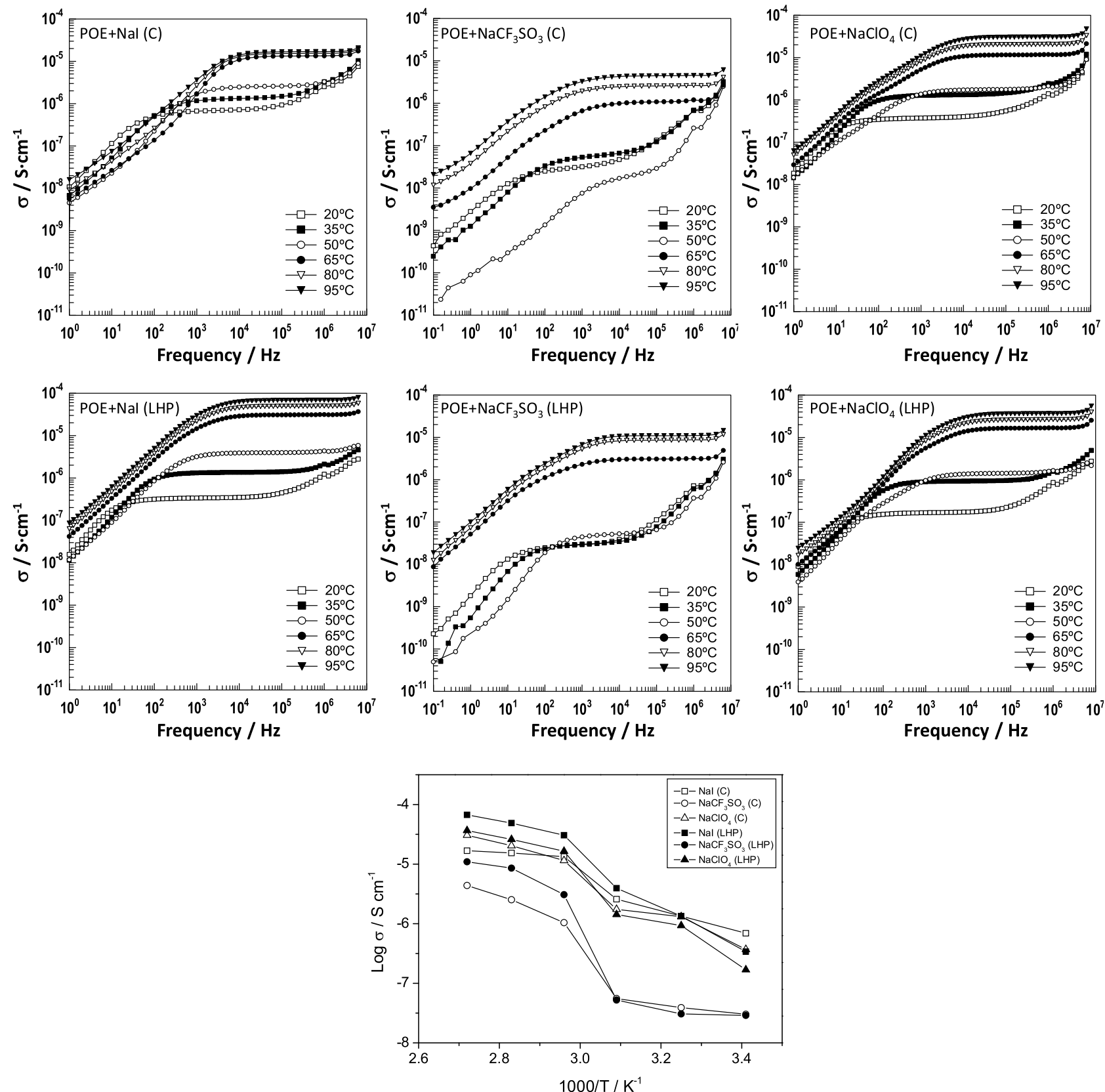

Fig. 6. Frequency dependent conductivity of POE-NaX electrolytes at different temperatures $\left(20-95^{\circ} \mathrm{C}\right)$ and conductivity $v s$ 1000/T plot. C: film-casting; LHP: lyophilization followed by hot-pressing. 
Given that the lyophilization procedure allows a very intimate blend of the electrolyte components in the powder to be obtained, this result cannot be attributed to a heterogeneous mixture of powders. It can therefore be inferred that LHP leads to a fully homogeneous distribution of the salt into the polymer backbone. Despite being simple to perform, film-casting involves a complex process of progressive evaporation of solvent. Indeed, it might be suspected that when the solvent progressively evaporates, the distribution of the salts between the amorphous phase and the crystalline one become heterogeneous, with enrichment in salt of the amorphous phase to the detriment of the crystalline one. The higher conductivity observed at room temperature for casted films are therefore probably related to a higher contribution of the amorphous electrolyte content.

\subsubsection{Temperature dependence of conductivity}

The frequency-dependent conductivity of electrolytes at different temperatures is depicted in Fig. 6. If we consider only one curve, three regions can be clearly observed: (i) a frequency dependent signal at the low frequency region; (ii) a plateau where signal becomes independent of frequency (dc conductivity); and (iii) a high frequency dispersion zone corresponding to bulk relaxation phenomena. At the low frequency region, a charge accumulation effect takes place at the electrode-electrolyte interface, reducing ions mobility, and therefore, conductivity. This phenomenon also produces the electrode polarization. For all electrolytes, as temperature increases, the dc ionic conductivity also increases and makes the electrode polarization effect more significant [56]. This is reflected by the shift of the plateau region towards higher frequency values. On the other hand, the mobility of the ionic charges increases at the high frequency region, leading to higher conductivity.

Surprisingly, independently of the polymer electrolyte, LHPprocessed films presented significantly higher conductivities than the casted ones in their amorphous state. As seen in Table 2 , which gathers conductivity obtained at $20^{\circ} \mathrm{C}, 65^{\circ} \mathrm{C}$ and $95^{\circ} \mathrm{C}$, the gap ranges between $19 \%$ and $\sim 400 \%$ at $95^{\circ} \mathrm{C}$.

\subsubsection{Concentration dependence of conductivity}

Despite $\mathrm{POE}-\mathrm{NaCF}_{3} \mathrm{SO}_{3}(\mathrm{O} / \mathrm{Na}=20)$ showed, independently of the film processing methodology, the lowest conductivity, this salt presents some advantages over $\mathrm{NaClO}_{4}$ and $\mathrm{NaI}$, including safety and electrochemical window stability, respectively. Moreover, we previously demonstrated that LHP, besides its environmental friendly nature, has significant advantages in terms of performance when compared to casting. Therefore, to investigate the concentration dependency of conductivity, we prepared, by LHP, POE$\mathrm{NaCF}_{3} \mathrm{SO}_{3}$ films with different O/Na ratios: 8, 12, 16, 20 and 25. Their conductivity was measured between 20 and $95^{\circ} \mathrm{C}$. Regarding electrolytes, conductivity depends both, on the concentration of ionic species that contribute to the conductivity, i.e. free-ions and solvent-separated ion-pairs, and on their mobility. When saltconcentration increases, the ion-pair dissociation decreases, but

Table 2

Conductivity at $20^{\circ} \mathrm{C}, 65^{\circ} \mathrm{C}$ and $95^{\circ} \mathrm{C}$ for all POE-NaX electrolytes.

\begin{tabular}{llll}
\hline \multirow{2}{*}{ Film } & \multicolumn{2}{l}{ Conductivity/S.cm } \\
\cline { 2 - 4 } & $20{ }^{\circ} \mathrm{C}$ & $65{ }^{\circ} \mathrm{C}$ & $95{ }^{\circ} \mathrm{C}$ \\
\hline $\mathrm{NaCF}_{3} \mathrm{SO}_{3}$ (C) & $3.0 \times 10^{-8}$ & $1.0 \times 10^{-6}$ & $4.4 \times 10^{-6}$ \\
$\mathrm{NaCF}_{3} \mathrm{SO}_{3}$ (LHP) & $2.9 \times 10^{-8}$ & $3.1 \times 10^{-6}$ & $1.1 \times 10^{-5}$ \\
$\mathrm{NaI}(\mathrm{C})$ & $6.9 \times 10^{-7}$ & $1.3 \times 10^{-5}$ & $1.7 \times 10^{-5}$ \\
$\mathrm{NaI}(\mathrm{LHP})$ & $3.4 \times 10^{-7}$ & $3.1 \times 10^{-5}$ & $6.7 \times 10^{-5}$ \\
$\mathrm{NaClO}_{4}$ (C) & $3.7 \times 10^{-7}$ & $1.2 \times 10^{-5}$ & $3.1 \times 10^{-5}$ \\
$\mathrm{NaClO}_{4}$ (LHP) & $1.7 \times 10^{-7}$ & $1.7 \times 10^{-5}$ & $3.7 \times 10^{-5}$ \\
\hline
\end{tabular}

C - film-casting. LHP - lyophilization followed by hot-pressing. the overall concentration in mobile ions increases. On the other hand, increasing salt-concentration also decreases segmental mobility, reducing the ion's mobility. The opposite effects concentration/mobility lead generally to a maximum or to maxima. Fig. $7 \mathrm{~A}$ shows that, at 20 and $65^{\circ} \mathrm{C}$, the highest conductivity was obtained for the concentration $\mathrm{O} / \mathrm{Na}=8$, just followed by $\mathrm{O} / \mathrm{Na}=12$. This result is supported by Fig. $7 \mathrm{~B}$ that compares the DSC records of the crystalline phase melting, which shows a broadening with two $\mathrm{T}_{\mathrm{m}}$ for the concentration $\mathrm{O} / \mathrm{Na}=8$. At $95^{\circ} \mathrm{C}$, the conductivity reaches $0.2 \mathrm{mS} \cdot \mathrm{cm}^{-1}$ both for $\mathrm{O} / \mathrm{Na}=8$ and 12 with a gap of roughly $2 \%$, i.e. in the margin of error.

\subsubsection{Polymer electrolyte based on sodium salts blends}

Even if $\mathrm{POE}-\mathrm{NaCF}_{3} \mathrm{SO}_{3}$ reached $0.2 \mathrm{mS} \cdot \mathrm{cm}^{-1}$, the sodium triflate does not allow decreasing significantly $\mathrm{T}_{\mathrm{m}}$ and, therefore, restricts the usable temperature range of Na-polymer batteries. Hence, retaining the same inexpensive components, we also explored the use of sodium salt blends with the aim of improving conductivity and decreasing polymer electrolyte crystallinity. Previously, Angell et al. [57] introduced the polymer-in salt concept, by mixing inorganic salts to produce molten salts later blended with small oligomer amounts, including PPG (polypropylene glycol) and PEG (polyethylene glycol). Nevertheless, despite improved conductivity, the high salt concentration led to polymer-in-salts with poor mechanical properties far from polymer/salt complexes endowed with a dual function of electrolyte and separator. To assess mixed-alkaline effect, Prudhomme et al. [58] investigated mixtures of alkaline salts, i.e. Li/K TFSI and Li/K SCN, hosted by POE oligomers and having the same anion. Alloin et al. [59] impregnated a 3D perfluorosulfonate based single Li-conducting polymer by LiTFSI to assess the possibility of stopping the TFSI anion mobility, but the cationic transference number, $\mathrm{T}^{+}$, was only doubled. On the other hand, Chauvin et al. [60] mixed a Li-conducting ionic liquid made of an oligo(oxyethylene) end-capped by a lithium sulfate ester moiety with LiTFSI and roughly tripled $\mathrm{T}^{+}$, while maintaining conductivity closed to the known optimal. Using crystalline forms of highly concentrated POE complexes, Bruce et al. [61] reported that an isovalent doping of only $5 \%$ of TFSI anion produced a conductivity gain of about 1.5 orders of magnitude. Their complexes, $\mathrm{POE}_{6}\left[\left(\mathrm{AsF}_{6(1-\mathrm{x})}-\mathrm{TFSI}_{\mathrm{x}}\right] \mathrm{Li}\right.$, were based on an $\alpha, \omega$ dimethyl-oligo(oxyethylene), well-below the entanglement threshold, obtained from the commercial PEG-1000. Despite the interest in terms of scientific knowledge, these materials are very far from polymer electrolytes targeted in lithium-polymer batteries.

In this preliminary study, we selected one concentration $(\mathrm{O} /$ $\mathrm{Na}=8)$ and tested two sodium salt blends: $\mathrm{NaI}+\mathrm{NaCF}_{3} \mathrm{SO}_{3}$ and $\mathrm{NaI}+\mathrm{NaClO}_{4}$, both in a 1:1 molar ratio. In both cases, TGA analyses revealed a delay of about $100^{\circ} \mathrm{C}\left(\mathrm{T}_{\text {onset }}\right.$ about $\left.400^{\circ} \mathrm{C}\right)$ in thermal degradation of the electrolyte when compared to polymer electrolytes based on a single salt. Table 3 summarizes $\mathrm{T}_{\mathrm{m}}, \mathrm{X}_{\mathrm{C}}$ and $\mathrm{T}_{\mathrm{g}}$ for both electrolytes.

Indeed, probably due to the increased disorder induced by the blends, melting temperature and crystallinity significantly decreased with regard to the electrolytes based on a single salt: $47^{\circ} \mathrm{C}$ and $20 \%$ for $\mathrm{POE}-\mathrm{NaI}+\mathrm{NaCF}_{3} \mathrm{SO}_{3}$ and $42{ }^{\circ} \mathrm{C}$ and $8 \%$ for POE$\mathrm{NaI}+\mathrm{NaClO}_{4}$ when compared to $58{ }^{\circ} \mathrm{C}$ and $31 \%$ for $\mathrm{POE}-\mathrm{NaCF}_{3} \mathrm{SO}_{3}$ at the same $\mathrm{O} / \mathrm{Na}$ ratio. As a result of crystallinity decrease, $\mathrm{T}_{\mathrm{g}}$ are significantly lower than those previously obtained and more representative of the segmental mobility above $T_{m}$. The Arrhenius plots of both polymer electrolytes are compared in Fig. 8.

The conductivity maxima of $\mathrm{POE}-\mathrm{NaCF}_{3} \mathrm{SO}_{3}+\mathrm{NaI}$, significantly lower than that of POE- $\mathrm{NaCF}_{3} \mathrm{SO}_{3}$, was deceiving. On the other hand, $\mathrm{POE}-\mathrm{NaI}+\mathrm{NaClO}_{4}$ exhibited a conductivity maximum 2.5 times higher than that of $\mathrm{POE}-\mathrm{NaClO}_{4}$ at the concentration $\mathrm{O} / \mathrm{Na}=20$. As $\mathrm{NaI}$ is present in both blends and as the relation $\mathrm{O} /$ $\mathrm{Na}=20$, the $\mathrm{POE} / \mathrm{NaI}$ is more conductive than $\mathrm{POE} / \mathrm{NaCF}_{3} \mathrm{SO}_{3}$, we 

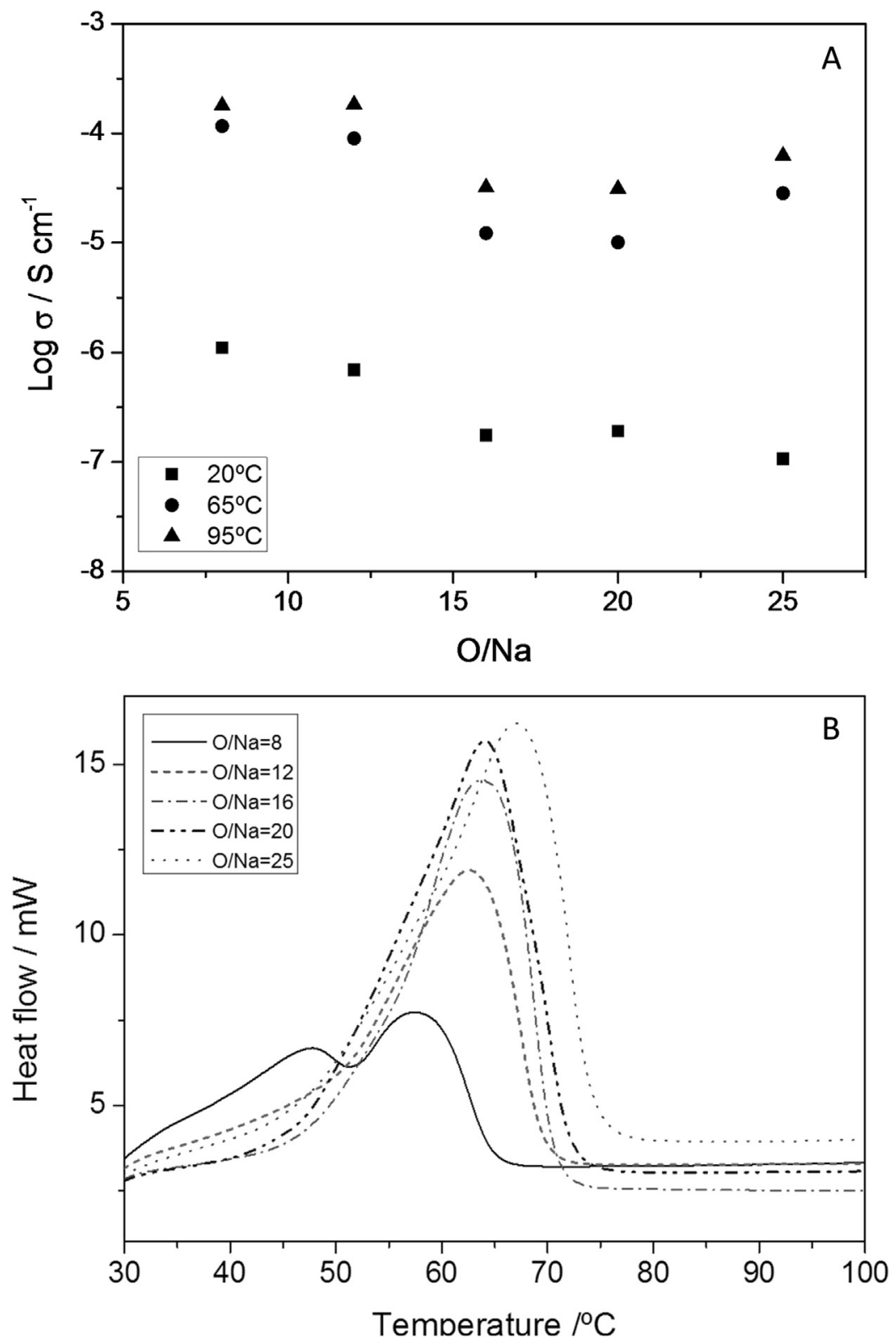

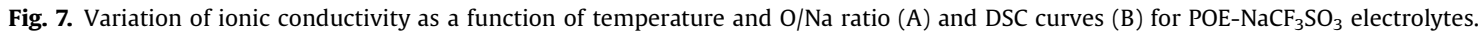

Table 3

$\mathrm{T}_{\mathrm{m}}, \mathrm{X}_{\mathrm{C}}$ and $\mathrm{T}_{\mathrm{g}}$ of POE electrolytes based on sodium salt blends.

\begin{tabular}{lllll}
\hline Film & $\mathrm{T}_{\mathrm{m}} /{ }^{\circ} \mathrm{C}$ & $\Delta \mathrm{H}_{\mathrm{m}} / \mathrm{J} \cdot \mathrm{g}^{-1}$ & $\mathrm{X}_{\mathrm{c}} / \%$ & $\mathrm{~T}_{\mathrm{g}} /{ }^{\circ} \mathrm{C}$ \\
\hline $\mathrm{POE}-\mathrm{NaI}+\mathrm{NaCF}_{3} \mathrm{SO}_{3}$ & 47.3 & 42 & 19.7 & -33.9 \\
$\mathrm{POE}-\mathrm{NaI}+\mathrm{NaClO}_{4}$ & 42.4 & 18 & 8.5 & -27.2 \\
\hline
\end{tabular}

propose two tentative explanations: 1) NaI decreases the dissociation of $\mathrm{Na}$ triflate and 2) the concomitant presence of both salts favors the formation of aggregates. If the conductivity results are mitigated, the effect of the blend on crystallinity is more promising and paves the way for optimized salt blends, e.g. Na triflate and NaTFSI, not only to decrease the overall cost, but also to enhance cationic conductivities. Indeed, due to the high delocalization of the anion charge [62] TFSI salts increase the conductivity of SPE, leading, at the same time, to low cationic transference numbers, $\mathrm{T}^{+}$. On the other hand, Li triflate leads to much higher $\mathrm{T}^{+}$ than LiTFSI [59]. The same trend is expected to occur with the $\mathrm{Na}$ salts. As the cationic conductivity, $\sigma^{+}$, is the product of the measured conductivity by $\mathrm{T}^{+}$, blending $\mathrm{Na}$ triflate and NaTFSI should optimize $\sigma^{+}$.

\subsection{Discussion}

In aprotic polymer electrolytes, the anion solvation by the host's polyether chains is negligible. Thus, pressure-temperature dependence of conductivity of single anion-conducting polymers allowed calculating the critical free volume $V_{f}^{*}$ [63] required for an elementary displacement. $V_{\mathrm{f}}{ }^{*}$ was found to be close to the known volume of halides and significantly lower than that of the TFSI anion, which was attributed to its flexibility [64], confirming the poor solvation ability of POE like hosts versus anions. Therefore, one of the most relevant parameters for polymer electrolytes is the polymer-cation interaction. Polymer electrolytes research having mainly focused on lithium polymer electrolytes, it may be feared that moving from $\mathrm{Li}^{+}$to $\mathrm{Na}^{+}, \mathrm{K}^{+}$or alkaline-earth cations, $\mathrm{Mg}^{2+}$ or $\mathrm{Ca}^{2+}$ result in lower conductivities and/or microphase separation. 


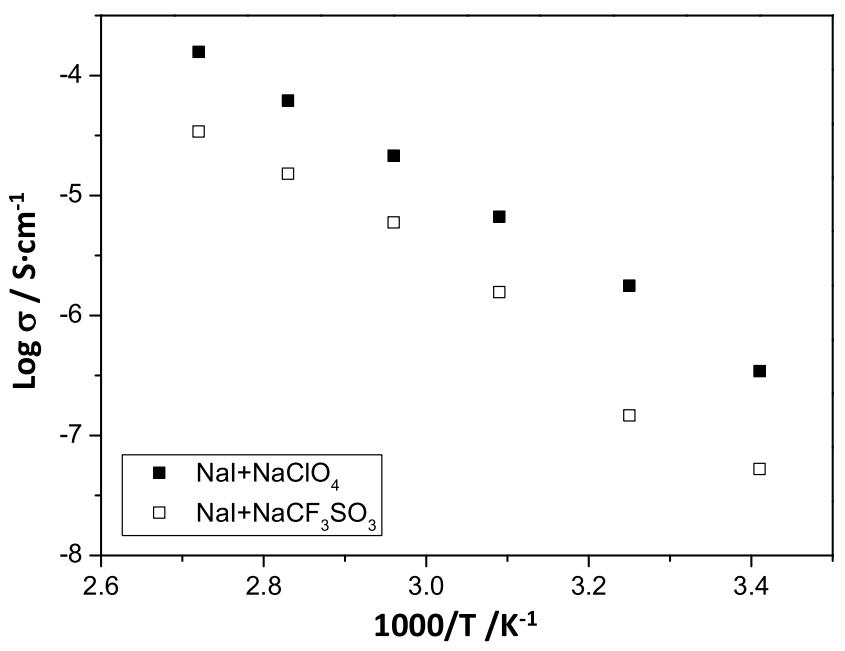

Fig. 8. Arrhenius conductivity plots of electrolyte blends: $\mathrm{POE}-\mathrm{NaI}+\mathrm{NaCF}_{3} \mathrm{SO}_{3}$ and $\mathrm{POE}-\mathrm{NaI}+\mathrm{NaClO}_{4}$.

In a first approach, conductivity of POE electrolytes decreases from $\mathrm{Li}^{+}$to $\mathrm{K}^{+}$. As for the radius, thus the volume, $\mathrm{V}_{\text {cat }}$, it increases with the atomic number: $0.5,2.1$ and $5.9 \mathrm{~cm}^{3} /$ mole for $\mathrm{Li}^{+}, \mathrm{Na}^{+}$and $\mathrm{K}^{+}$, respectively. Although, the three alkaline cations are Hard Acids, the chemical hardness decreases with the atomic number, e.g. 35.1 and $21.1 \mathrm{eV}$ for $\mathrm{Li}^{+}$and $\mathrm{Na}^{+}$, respectively [65]. Furthermore, though triflate anion is slightly softer than trifluoromethane sulfonyl imide $\left(\mathrm{TFSI}^{-}\right)$, its absolute hardness, calculated from Koopman's theorem, remains high enough to favor the formation of ion-pairs [62]. Therefore, moving from $\mathrm{Li}^{+}$to $\mathrm{Na}^{+}$and $\mathrm{K}^{+}$, i.e. to softer cations, should favor the ion-pair dissociation. However, since conductivity depends both on ion-pair dissociation and on ionic mobility, one assumption, to explain the decrease in conductivity observed by moving from $\mathrm{Li}^{+}$to $\mathrm{Na}^{+}$and later to $\mathrm{K}^{+}$, would be to attribute it to a decrease in segmental mobility, i.e. a $\mathrm{T}_{\mathrm{g}}$ increase. The high crystallinity of the POE difficults accessing to reliable $T_{g}$ representative of segmental mobility, since the crystalline phase constrains the amorphous one. On the other hand, a previous comparative study regarding conductivity of alkali TFSI [31] performed on fully amorphous cross-linked POE (NPOE) evidenced that both $\mathrm{Na}^{+}$and $\mathrm{K}^{+}$amorphous polymer electrolytes have indeed lower $\mathrm{T}_{\mathrm{g}}$ than Li ones e.g. at $\mathrm{O} / \mathrm{M}=20$, $-52,-57$ and $-56^{\circ} \mathrm{C}$ for LiTFSI, NaTFSI and KTFSI electrolytes, respectively. Regarding maximal conductivity in N-POE/M-TFSI electrolytes, it was found to decrease according to LiTFSI > NaTFSI > KTFSI at high salt concentrations $\mathrm{O} / \mathrm{M} \leq 16$. However, this order was found to change at $\mathrm{O} / \mathrm{M}=20$, where the three electrolytes reached the same conductivity and, beyond that value, a reverse order KTFSI $>$ NaTFSI $>$ LiTFSI was observed. In accordance with these results, it could be inferred that moving from lithium to other alkaline cations should neither be detrimental to segmental mobility nor to ionic conductivity. This is in agreement with the decrease in the polarizing effect of the alkaline cation when the atomic number increases. Moreover, temperature and pressure conductivity-dependence measurements performed on singlecation-conducting networks based on a perfluorosulfonate similar to triflate anion [66] sustain this hypothesis. Indeed, critical free volumes $\left(V_{f}^{*}\right)$ of $7.7,9.7 \mathrm{~cm}^{3}$ were calculated for $\mathrm{Li}^{+}, \mathrm{Na}^{+}$, in line with the cation volume, $V_{\text {cat }}$, but the ratio $V_{f}^{*} / V_{\text {cat }}$ decreases according to $\mathrm{Li}^{+}$(15.4) $>\mathrm{Na}^{+}$(4.6), emphasizing a stronger polarizing effect of $\mathrm{Li}^{+}$. It can be therefore inferred that sodium salts hosted by POE should neither be less dissociated than their lithium analogs nor induce a decrease in segmental mobility of POE electrolytes. Therefore, both the cationic transference numbers $\mathrm{T}^{+}$ and the cationic conductivities $\sigma^{+}=\sigma \cdot \mathrm{T}^{+}$should increase with the cation size. This assumption is supported by the experimental data of (i) Chauvin et al. [67], who reported POE ionomers with $\mathrm{T}^{+}$ ranging between 0.6 and 0.9 and whose conductivities increased with the cation size according to $\mathrm{Li}^{+}<\mathrm{Na}^{+}<\mathrm{K}^{+}<\mathrm{Cs}^{+}$and (ii) Ohno et al. [68] regarding oligoethers end-capped by carboxylate anions. Consequently, the host polymer morphology is probably one of the deciding parameters to enhance, at ambient temperature, the conductivity of $\mathrm{Na}$ polymer electrolytes.

\section{Conclusions}

The main target of this contribution was to assess the performance of sodium-conducting solvent-free polymer electrolytes based on available and fairly inexpensive materials, while using a solvent-free green process for films preparation. Films were successfully processed by hot-pressing from homogeneous powders of POE-NaX salts prepared by lyophilization. These films exhibited enhanced homogeneity, tensile strength and conductivity, when compared to casted ones. However, despite the reinforcement induced by $\mathrm{Na}^{+}$interchain solvation, a creeping of the polymer electrolytes from roughly $90^{\circ} \mathrm{C}$ is incompatible with the safety requirements of a Na-polymer battery. Regarding conductivity, performances are still limited but pave the way for improved Na-polymer electrolytes, moving from linear semicrystalline POE to cross-linked ones in order to get fully amorphous polymer electrolytes based either on single salts or on salt mixtures.

\section{Acknowledgements}

This work has been supported by Projects funded by the regional government (Comunidad de Madrid through MATERYENER3CM S2013/MIT-2753) and the Spanish Government, MICINN (MAT2013-46452-C4-3R).

J-Y Sanchez acknowledges Universidad Carlos III de Madrid for awarding him a European Chair of Excellence and the CONEX Programme funding, received from Universidad Carlos III de Madrid, the European Union's Seventh Framework Programme for research, technological development and demonstration (Grant agreement $n^{\circ}$ 600371), Spanish Ministry of Economy and Competitiveness (COFUND2013-40258) and Banco Santander.

\section{References}

[1] J.M. Tarascon, Is lithium the new gold? Nat. Chem. 2 (6) (2010) 510.

[2] R. Van Noorden, A better battery, Nature 507 (7490) (2014) 26.

[3] Bolivia, Chili and Argentina now gathered in OPPROLI (Organización de los Países Productores de Litio), organization similar to OPEC (Organization of the Petroleum Exporting Countries).

[4] D. Linden, T.R. Reddy, Handbook of batteries, 3rd edition, McGraw-Hill, 1995 Table.1.1.

[5] C. Delmas, J.J. Braconnier, C. Fouassier, P. Hagenmuller, Electrochemical intercalation of sodium in $\mathrm{NAXCOO}_{2}$ bronzes, Solid. State Ionics 3-4 (1981) 165.

[6] L. Shacklette, T.L. Jow, L. Townsend, Rechargeable electrodes from sodium cobalt bronzes, J. Electrochem. Soc. 135 (11) (1988) 2669.

[7] V. Palomares, P. Serras, I. Villaluenga, K.B. Hueso, J. Carretero-Gonzalez, T. Rojo, Na-ion batteries, recent advances and present challenges to become low cost energy storage systems, Energy Environ. Sci. 5 (3) (2012) 5884

[8] S.W. Kim, D.H. Seo, X. Ma, G. Ceder, K. Kang, Electrode materials for rechargeable sodium-ion batteries: potential alternatives to current lithiumion batteries, Adv. Energy Mater. 2 (7) (2012) 710.

[9] B.F. Ellis, L.F. Nazar, Sodium and sodium-ion energy storage batteries, Curr. Opin. Solid State Mat. Sci. 16 (4) (2012) 168.

[10] D. Linden, T.R. Reddy, Handbook of batteries, 3rd edition, McGraw-Hill, 1995

[11] J. Sudworth, R. Tilley, The sodium/sulfur battery, Chapman and Hall, London, 1985.

[12] J. Coetzer, A new high-energy density battery system, J. Power Sources 18 (4) (1986) 377.

[13] R. Galloway, S. Haslam, The ZEBRA electric vehicle battery: power and energy improvements, J. Power Sources 80 (1-2) (1999) 164 
[14] P.E. Stallworth, J. Li, S.G. Greenbaum, F. Croce, S. Slane, M. Salomon, Na- ${ }^{23} \mathrm{NMR}$ and complex impedance studies of gel electrolytes based on poly (acrylonitrile), Solid State Ionics 73 (1-2) (1994) 119.

[15] M. Egashira, T. Asai, N. Yoshimoto, M. Morita, Ionic conductivity of ternary electrolyte containing sodium salt and ionic liquid, Electrochimica Acta 58 (2011) 95

[16] A. Bhide, J. Hofmann, A.K. Dürr, J. Janek, P. Adelhelm, Electrochemical stability of non-aqueous electrolytes for sodium-ion batteries and their compatibility with $\mathrm{Na}_{0.7} \mathrm{CoO}_{2}$, Phys. Chem. Chem. Phys. 16 (5) (2014) 1987.

[17] D. Kumar, S.A. Hashmi, Ionic liquid based sodium ion conducting gel polymer electrolytes, Solid State Ionics $181(8-10)(2010) 416$.

[18] C. Ding, N. Toshiyuki, R. Hagiwara, K. Matsumoto, Y. Okamoto, A. Fukunaga, S. Sakai, K. Nitta, S. Inazawa, Na[FSA-C(3)C(1) pyrr][FSA] ionic liquids as electrolytes for sodium secondary batteries: effects of Na ion concentration and operation temperature, J. Power Sources 269 (2014) 124.

[19] C. Cao, W. Liu, L. Tan, X. Liao, L. Li, Sodium-ion batteries using ion exchange membranes as electrolytes and separators, Chem. Commun. 49 (2013) 11740

[20] H.Gao,B.Guo,J.Song,K.Park,J.B.Goodenough,Acompositegel-polymer/glassfiberelectrolyteforsodium-ionbatteries,Adv.EnergyMater.5(2015) 1402235.

[21] F. Bella, F. Colò, J.R. Nair, C. Gerbaldi, Photopolymer electrolytes for Sustainable, upscalable, safe, and ambient-temperature sodium-ion secondary batteries, ChemSusChem 8 (2015) 3668.

[22] D.E. Fenton, J.M. Parker, P.V. Wright, Complexes of alkali-metal ions with poly (ethylene oxide), Polymer 14 (11) (1973) 589

[23] P.V. Wright, Electrical conductivity in ionic complexes of poly (ethylene oxide) Br. Polym. J. 7 (1975) 319.

[24] J.M. Parker, P.V. Wright, C.C. Lee, A double helical model for some alkali-metal ion-poly(ethylene oxide) complexes, Polymer 22 (10) (1981) 1305

[25] C.C. Lee, P.V. Wright, Morphology and ionic-conductivity of complexes of sodium-iodide and sodium thiocyanate with poly(ethylene oxide), Polymer 23 (5) (1982) 681.

[26] K.Ramamohan,V.B.S.Acheri,A.K.Sherma,X.Y.Lu,Electricalandstructural characterizationofPVA/PEG polymlerblendelectrolytefilmsdopedwith $\mathrm{NaClO}_{4}$ Ionics21(2015)1333.

[27] Z. Osman, K.B.M. Isa, A. Ahmad, L. Othman, A comparative study of lithium and sodium salts in PAN-based ion conducting polymer electrolytes, Ionics 16 (5) (2010) 431.

[28] N. Chaix, F. Alloin, J.P. Bélières, J. Saunier, J.Y. Sanchez, Electrochemical study of polymethacrylonitrile electrolytes - Comparative investigation of polynitriles electrochemical stability through model molecules. Part II, Electrochimica Acta. 47 (8) (2002) 1327.

[29] J.P. Belières, M. Marechal, J. Saunier, F. Alloin, J.Y. Sanchez, Swollen polymethacrylonitrile urethane networks for lithium batteries, J. Electrochem. Soc. 150 (1) (2003) A14.

[30] J.S. Moreno, M. Armand, M.B. Berman, S.G. Greenbaum, B. Scrosati, S. Panero, Composite PEOn:NaTFSI polymer electrolyte: preparation, thermal and electrochemical characterization, J. Power Sources 248 (2014) 695.

[31] F. Alloin, J.-Y. Sanchez, M. Armand, New solvating cross-linked polyether for lithium batteries, J. Power Sources 54 (1) (1995) 34 [32] A. Boschin, P. Johansson, Characterization of NaX (X: TFSI FSI) - PEO based solid
polymer electrolytes for sodium batteries, Electrochimica Acta 175 (2015) 124.

[33] F.Colò,F.Bella,J.R.Nair,M.Destro,C.Gerbaldi,Cellulose-basednovelhybrid polymerelectrolytesforgreenandefficientNa-ionbatteries,Electrochimica Acta 174(2015) 185.

[34] Y. Ni'mah, M.Y. Cheng, J.H. Cheng, J. Rick, B.J. Hwang, Solid-state polymer nanocomposite electrolyte of $\mathrm{TiO}_{2} / \mathrm{PEO} / \mathrm{NaClO}_{4}$ for sodium ion batteries, J. Power Sources 278 (2015) 375.

[35] M.A.S.F.A. Samir, F. Alloin, J.-Y. Sanchez, A. Dufresne, Cross-linked nanocomposite polymer electrolytes reinforced with cellulose whiskers, Macromolecules 37 (13) (2004) 4839.

[36] F. Alloin, J.-Y. Sanchez, Partial hydrogenation of unsatured polyethers: A convenient oute to curable terpolymers for lithium batteries, J. Polym. Sci. Part. A. 16 (2000) 2900.

[37] F. Alloin, J.Y. Sanchez, New solvating polyether networks, Electrochimica Acta $40(13-14)$ (1995) 2269.

[38] N. Boaretto, A. Bittner, C. Brinkmann, B.E. Olsowski, J. Schulz, M. Seyfried, K. Vezzù, M. Popall, V. Di Noto, Highly conducting 3D-hybrid polymer electrolytes for lithium batteries based on siloxane networks and cross-linked organic polar interphases, Chem. Mater 26 (2014) 6339.

[39] F.Bossard,N.ElKissi,A.D’Aprea,F.Alloin,J.-Y.Sanchez,A.Dufresne,Influence of dispersionprocedureonrheologicalpropertiesofaqueoussolutionsofhigh molecularweightPEO,Rheol.Acta49(5)(2010)529.

[40] B. Bhattacharya, R.K. Nagarale, P.K. Singh, Effect of sodium-mixed anion doping in PEO-based polymer electrolytes, High Perform. Polym. 22 (4) (2010) 498

[41] S.A.M.Noor,A.Ahmad,M.Y.A.Rahman,I.A.Talib,Solidpolymericelectrolyteof the poly(ethylene)oxide-50\%epeoxidizednaturalrubber-lithiumtriflate, Natural Science2(2010)190.
[42] L.Assumma,H.D.Nguyen,C.Iojoiu,S.Lyonnard,R.Mercier,E.Espuche,Effects of blocklengthandmembraneprocessingconditionsonthemorphologyand propertiesofperfluorosulfonatedpoly(aryleneethersulfone)multiblock copolymermembranesforPEMFC,ACSAppliedMaterials\&Interfaces7(25)(2015) 13808.

[43] J.Y. Sanchez, F. Chabert, C. Iojoiu, J. Salomon, N. El Kissi, Y. Piffard, M. Marechal, H. Galiano, R. Mercier, Extrusion: an environmentally friendly process for PEMFC membrane elaboration, Electrochimica Acta 53 (4) (2007) 1584

[44] Y. Molmeret, F. Chabert, N. El Kissi, C. Iojoiu, R. Mercier, J.Y. Sanchez, Towards extrusion of ionomers to process fuel cell membranes, Polymers 3 (3) (2011) 1126.

[45] M.Bonnet,C.Gavach,P.Geneste,P.Graffin,J.Y.Sanchez,Electron-transfer through polyethylene,graphitecharged,membranes,JournaldeChimie-Physique74 $(11-1)(1977) 1192$

[46] G.B. Appetecchi, F. Croce, G. Dautzemberg, M. Mastragostino, F. Ronsi, F. Soavi, A. Zanelli, F. Alessandrini, P.P. Prosini, Composite polymer electrolytes with improved lithium metal electrode interfacial properties - I. Electrochemical properties of dry PEO-LiX systems, J. Electrochem. Soc. 145 (12) (1998) 4126.

[47] K.I. Izutsu, N. Aoyagi, Effect of inorganic salts on crystallization of poly (ethylene glycol) in frozen solutions, Int. J. Pharm. 288 (1) (2005) 101.

[48] M. Chintapalli, X.C. Chen, J.L. Thelen, A.A. Teran, X. Wang, B.A. Garetz, N.P. Balsara, Effect of grain size on the ionic conductivity of a block copolymer electrolyte, Macromolecules 47 (15) (2014) 5424.

[49] P.P. Chu, M.J. Reddy, H.M. Kao, Novel composite polymer electrolyte comprising mesoporous structured $\mathrm{SiO}_{2}$ and PEO/Li, Solid State Ion. 156 (1-2) (2003) 141.

[50] P.B.Bhagav,V.M.Mohan,A.K.Sharma,Structuralandelectricalpropertiesof pure andNaBrdopedpoly(vinylalcohol)(PVA)polymerelectrolytefilmsfor solidstate batteryapplications,Ionics13(6)(2007)173.

[51] R.M.Hodge,G.H.Edward,G.P.Simon,Waterabsorptionandstatesofwaterin semicrystallinepoly(vinylalcohol)films,Polymer37(8)(1996)1371.

[52] G.G. Cameron, M.D. Ingram, M.Y. Qureshi, H.M. Gearing, L. Costa, G. Camino, The thermal-degradation of poly(ethylene oxide) and its complex with NaCNS Eur. Polym. J. 25 (7-8) (1989) 779.

[53] J. Moacanin, E.F. Cuddihy, Effect of polar forces on the viscoelastic properties of poly(propylene oxide), J.Polym.Sci.C. 14 (1) (1966) 313.

[54] C. Vachon, C. Labreche, A. Vallee, S. Besner, M. Dumont, J. Prudhomme, Microphase Separation and Conductivity Behavior of Poly(propylene oxide)Lithium Salt Electrolytes, Macromolecules 28 (16) (1995) 5585.

[55] E.Paillard,C.Iojoiu,F.Alloin,J.Guindet,J.Y.Sanchez,Poly(oxyethylene) electrolytesbasedonlithiumpentafluorobenzenesulfonate,Electrochimica Acta 52(11)(2007)3758.

[56] D.K. Pradhan, R.N.P. Choudhary, B.K. Samantaray, Studies of structural, thermal and electrical behavior of polymer nanocomposite electrolytes, Express Polym Lett. 2 (9) (2008) 630.

[57] C.A. Angell, C. Liu, E. Sanchez, Rubbery solid electrolytes with dominant cationic transport and high ambient conductivity, Nature 362 (6416) (1993) 137.

[58] M. Perrier, S. Besner, C. Paquette, A. Vallée, S. Lascaud, J. Prudhomme, Mixedalkali effect and short-range interactions in amorphous poly(ethylene oxide) electrolytes, Electrochimica Acta $40(13-14)(1995) 2123$.

[59] F. Alloin, D. Benrabah, J.Y. Sanchez, Comparative ion transport in several polymer electrolytes, J. Power Sources 68 (2) (1997) 372

[60] C. Chauvin, F. Alloin, P. Judeinstein, D. Foscallo, J.Y. Sanchez, Electrochemical and NMR characterizations of mixed polymer electrolytes based on oligoether sulfate and imide salts, Electrochimica Acta 52 (3) (2006) 1240

[61] A.M. Christie, S.L. Lilley, E. Staunton, Y.G. Andreev, P.G. Bruce, Increasing the conductivity of crystalline polymer electrolytes, Nature 433 (7021) (2005) 50

[62] D. Benrabah, R. Arnaud, J.Y. Sanchez, Comparative ab-initio calculations on several salts, Electrochimica Acta 40 (13-14) (1995) 2437.

[63] M.H. Cohen, D. Turnbull, Molecular transport in liquids and glasses, J. Chem. Phys. 31 (5) (1959) 1164

[64] M. Duclot, F. Alloin, O. Brylev, J.-Y. Sanchez, J.-L. Souquet, Transport mechanism in anionic conductive ionomers from temperature and pressure conductivity measurements, Electrochimica Acta 50 (25-26) (2005) 5015.

[65] R.G. Parr, R.G. Pearson, Absolute hardness - Companion parameter to absolute

[66] M. Duclot, F. Alloin, O. Brylev, J.Y. Sanchez, J.L. Souquet, New alkali ionomers: transport mechanism from temperature and pressure conductivity measurements, Solid State Ionics 136 (2000) 1153.

[67] C. Chauvin, C. Iojoiu, F. Alloin, J.Y. Sanchez, New polymer electrolytes based on ether sulfate anions for lithraveium polymer batteries - Part I. Multifunctional ionomers: Conductivity and electrochemical stability, Electrochimica Acta 51 (26) (2006) 5876

[68] H. Ohno, N. Kobayashi, S. Takeoka, H. Ishikaza, E. Tsuchida, Larger cations can move faster in solid polymer electrolytes, Solid State Ionics 40-1 (1990) 655. 